\title{
Assessment of Natural Radioactivity Levels and Radiological Hazards of Cement in Iraq
}

\author{
Zaki A. Mansoor ${ }^{1}$, Takrid Muneam Nafae ${ }^{1}$, Ali Kareem K. Jelaot ${ }^{2}$ \\ ${ }^{1}$ Radiation Protection Department, Ministry of Science and Technology, Baghdad, Iraq \\ ${ }^{2}$ Nuclear Safety Department, Ministry of Science and Technology, Baghdad, Iraq
}

Email address:

Zeki_alqaisy@yahoo.com (Z. A. Mansoor)

\section{To cite this article:}

Zaki A. Mansoor, Takrid Muneam Nafae, Ali Kareem K. Jelaot. Assessment of Natural Radioactivity Levels and Radiological Hazards of Cement in Iraq. Nuclear Science. Vol. 3, No. 2, 2018, pp. 23-27. doi: 10.11648/j.ns.20180302.11

Received: September 27, 2018; Accepted: October 10, 2018; Published: November 5, 2018

\begin{abstract}
Eight samples of cement were collected from different commercial factories (Al-Koufa, Al-Basra, Al-Najaf and Kerkouk factories) located in Iraq. They were analyzed using a gamma ray spectroscopy system. The activity concentrations of ${ }^{226} \mathrm{Ra}^{232}{ }^{2} \mathrm{Th}$ and ${ }^{40} \mathrm{~K}$ were ranged from 5.8 to $43.17 \mathrm{~Bq} \mathrm{~kg}^{-1}$, from 0.99 to $55.79 \mathrm{~Bq} \mathrm{~kg}^{-1}$ and from 53.28 to $185.34 \mathrm{~Bq} \mathrm{~kg}{ }^{-1}$, respectively. The potential radiological hazards were assessed by calculating the radium equivalent activity $\left(\mathrm{Ra}_{\mathrm{eq}}\right)$, the indoor absorbed gamma dose rate (D), the annual effective dose equivalent (AEDE), the alpha index $\left(\mathrm{I}_{\alpha}\right)$, the gamma index $\left(\mathrm{I}_{\gamma}\right)$, and the external hazard $\left(\mathrm{H}_{\mathrm{ex}}\right)$ and internal hazard $\left(\mathrm{H}_{\mathrm{in}}\right)$ indices. The highest value of $\mathrm{Ra}_{\mathrm{eq}}$ is estimated of $101.36 \mathrm{~Bq} \mathrm{~kg}$, which is significantly less than the upper limit of $370 \mathrm{~Bq} \mathrm{~kg}^{-1}$. The estimated maximum value of the absorbed gamma dose rate of 54.71 $\mathrm{nGy} \mathrm{h}^{-1}$ is within the world average value of $55 \mathrm{nGy} \mathrm{h}^{-1}$, and the annual effective dose equivalent in the studied samples were 0.05 (outdoor), 0.18 (indoor) $\mathrm{mSv} \mathrm{y}^{-1}$, which is lower than the recommended limit reported in the UNSCEAR (2000). The values of the hazard indices were below the recommended levels; therefore, the study shows that the measured radioactivity for cement does not pose as significant source of radiation hazard and is safe for use in the construction of dwellings.
\end{abstract}

Keywords: Gamma Ray Spectroscopy, Building Materials, Hazard Index

\section{Introduction}

The human population is always exposed to ionizing radiation due to background radiation. The main source of background radiation is naturally occurring radioactive materials (NORM). The natural radioactivity in soil and building materials mainly comes from uranium $\left({ }^{238} \mathrm{U}\right)$ series, thorium $\left({ }^{232} \mathrm{Th}\right)$ series and a radioactive isotope of potassium $\left({ }^{40} \mathrm{~K}\right)$ (These radionuclides can be found almost in all types of rocks, sand, cement and gypsum from which building materials are produced) [1-3]. All of these natural sources of radioactivity can be sources of both internal and external radiation exposure. Internal exposure occurs through the inhalation of radon gas and its progeny, which emit alpha particles, are the most significant radionuclides that diffuse from building materials into the indoor environments. The radionuclide ${ }^{226} \mathrm{Ra}$, with a half-life of 1600 years [4], is a source of the radioactive inert gas radon $\left({ }^{222} \mathrm{Rn}\right)$, which emits alpha and beta particles, followed by gamma radiation. And external exposure occurs through the emission of penetrating gamma rays from radioactive sources. Therefore, it is important to measure the radioactivity levels in the built-up areas to assess the radiological consequences $[5,6]$. It is known that the cement is a large part of most buildings and as most people spending approximately $80 \%$ of their lifetimes surrounded by building materials at home and/or at the office [7]. Therefore, it is important to know the radioactivity in building materials, especially the cement to estimate radiation risks to human health

The knowledge of the radioactivity present in construction materials helps to assess the possible radiological hazards to human health and develop the standards and guidelines for the use and management of these materials.

In this study, the concentrations of natural radionuclides were measured in 8 samples of cement from national commercial factories in Iraq, by means of gamma ray spectrometry, with the aim of assessing the radiological hazards due to external gamma ray exposure in dwellings. 
The potential radiological hazards associated with these materials were assessed by calculating the radium equivalent activity $\left(\mathrm{Ra}_{\mathrm{eq}}\right)$, the indoor absorbed gamma dose rate $(\mathrm{D})$, the annual effective dose equivalent (AEDE), the activity utilization index, the external hazard $\left(\mathrm{H}_{\mathrm{ex}}\right)$, the gamma index $\left(\mathrm{I}_{\gamma}\right)$, internal hazard $\left(\mathrm{H}_{\mathrm{in}}\right)$ and the alpha index $\left(\mathrm{I}_{\alpha}\right)$ indices.

\section{Laboratory Measurements}

\subsection{Sampling}

Eight samples of cement (the common building material) were collected from eight different commercial factories located in Iraq. The sampling locations were chosen according to the factories. Four locations in the district were chosen for this investigation, Al-Koufa, Al-Basra, Al-Najaf and Kerkouk. The cement samples were taken directly from the factories in these governorates that was studied in its natural form. Each sample was properly marked and coded according to its origin and the location of the sampling site. The collected samples were dried in an oven at $80^{\circ} \mathrm{C}$ for 8 hours to remove the moisture from the samples. Approximately $500 \mathrm{~g}$ of each sample was sealed into a Marinelli beaker and stored for a period of 30 days at room temperature to allow secular equilibrium between ${ }^{226} \mathrm{Ra}$ and its progeny species to be achieved prior to gamma spectroscopy [8].

\subsection{Radionuclide Analysis}

The activity concentrations of $238 \mathrm{U}, 232 \mathrm{Th}$ and $40 \mathrm{~K}$ of the collected samples were measured using gamma spectrometry system. These measurements were occurred at Iraq- the Ministry of Science \& Technology. The Gamma spectrometry system consist of High-Purity Germanium (HPGe) detector with an efficiency of (40\%) and resolution 2 $\mathrm{keV}$ at $1.332 \mathrm{MeV}$ gamma ray photo peak of 60Co source, the data are collected using digital spectrum analyzer (DSA2000). Calibration and efficiency of the system was carried out using multi-gamma ray standard sources (MGS-5 Canberra, activity $1.1 \mu \mathrm{Ci}$, made in 2004) of Marinelli Beaker geometry. The analysis samples were conducted by dedicated software programme (Genie-2000, USA). Each sample was measured for one hour [9].

\section{Estimation of Radiation Hazard Indicators}

To assess the excess gamma radiation originating from building materials, several hazard indices have been suggested by a number of investigators; these calculations include the absorbed gamma dose rate in the indoor environment and the corresponding annual effective dose equivalent, the radium equivalent activity, the external and internal hazard indices, the alpha index (internal index) and the gamma activity concentration (gamma index). In the present study, the aforementioned hazard indicators were estimated for individuals living in domestic dwellings and for individuals at the workplace to evaluate the potential radiation risks arising from the use of the studied building materials.

\subsection{Assessment of the Radium Equivalent Activity (Raeq)}

The relative concentrations of ${ }^{226} \mathrm{Ra},{ }^{232} \mathrm{Th}$ and ${ }^{40} \mathrm{~K}$ are not uniform in environmental media. Accordingly, the distributions of the ${ }^{226} \mathrm{Ra},{ }^{232} \mathrm{Th}$ and ${ }^{40} \mathrm{~K}$ radionuclides were not found to be uniform in the studied building materials. A non-uniform distribution of radioactivity in materials containing $\mathrm{Ra}$, Th and $\mathrm{K}$ can be modelled using a general index $\mathrm{Ra}_{\mathrm{eq}}$ (radium equivalent activity), Raeq was computed using Eq (1) $[10,11]$.

$$
\mathrm{Ra}_{\mathrm{eq}}=\mathrm{A}_{\mathrm{Ra}}+1.43 \mathrm{~A}_{\mathrm{Th}}+0.077 \mathrm{~A}_{\mathrm{K}}
$$

Where $A_{\text {Ra }}, A_{T h}$ and $A_{K}$ (in $B q k^{-1}$ ) are the activity concentrations of ${ }^{226} \mathrm{Ra},{ }^{232} \mathrm{Th}$ and ${ }^{40} \mathrm{~K}$, respectively. Eq (1) is based on the assumption that $1 \mathrm{~Bq} \mathrm{~kg}^{-1}$ of ${ }^{238} \mathrm{U}, 0.7 \mathrm{~Bq} \mathrm{~kg}^{-1}$ of ${ }^{232} \mathrm{Th}$ and $13 \mathrm{~Bq} \mathrm{~kg}^{-1}$ of ${ }^{40} \mathrm{~K}$ produce the same gamma-ray dose rates [10].

\subsection{Absorbed Gamma Dose Rate (D)}

The outdoor absorbed dose rate $\left(\mathrm{nGy} \mathrm{h}^{-1}\right)$ in air from terrestrial gamma radiation at $1 \mathrm{~m}$ above the ground is calculated after applying the conversion factors (in $\mathrm{nGy} \mathrm{h}^{-1}$ per $\mathrm{Bq} \mathrm{kg}{ }^{-1}$ ) to transform the specific activities $\mathrm{A}_{\mathrm{Ra}}, \mathrm{A}_{\mathrm{Th}}$ and $A_{K}$ into the absorbed dose rate according to the formula provided by UNSCEAR and European Commission $[12,13]$.

$$
\mathrm{D}(\mathrm{nGy} \mathrm{h}-1)=0.5 \mathrm{~A}_{\mathrm{Ra}}+0.75 \mathrm{~A}_{\mathrm{Th}}+0.05 \mathrm{~A}_{\mathrm{K}}
$$

\subsection{Annual Effective Dose Equivalent (AEDE)}

To estimate the annual effective dose rate, it is necessary to use the conversion coefficient from the absorbed dose in air to the effective dose $(0.7 \mathrm{~Sv}$ Gy-1) and the outdoor and indoor occupancy factor 0.2 and 0.8 , respectively, proposed by UNSCEAR [14]. Therefore, the effective dose rate is determined as follows [12]:

$$
\begin{gathered}
\text { Outdoor: }\left(\mathrm{mSv} \mathrm{y}^{-1}\right)=\mathrm{D}\left(\mathrm{nGy} \mathrm{h}^{-1}\right) \times 8760 \mathrm{~h} \times 0.2 \times 0.7 \mathrm{~Sv} \\
\mathrm{~Gy}^{-1} \times 10^{-6}
\end{gathered}
$$

Indoor: $\left(\mathrm{mSv} \mathrm{y}^{-1}\right)=\mathrm{D}\left(\mathrm{nGy} \mathrm{h}^{-1}\right) \times 8760 \mathrm{~h} \times 0.8 \times 0.7 \mathrm{~Sv} \mathrm{~Gy}^{-1}$

$$
\times 10^{-6}
$$

Where $\mathrm{D}$ is the dose rate in $\mathrm{nGy} \mathrm{h}^{-1}$.

\subsection{Hazard Indices}

\subsubsection{Hazard Indices for External Gamma Radiation (Hex \& $\left.I_{\gamma}\right)$}

For the assessment of excess gamma radiation, to assess gamma radiation for building materials, two indices were used in this paper. The hazard index for the external gamma radiation dose from building materials as given below [10]:

$$
\mathrm{Hex}=\mathrm{A}_{\mathrm{Ra}} / 370+\mathrm{A}_{\mathrm{Th}} / 259+\mathrm{A}_{\mathrm{K}} / 4810
$$


The value of Hex should be below 1 to ensure the safe use of building materials, which corresponds to the upper limit of Raeq $\left(370 \mathrm{~Bq} \mathrm{~kg}^{-1}\right)$. The European Commission (EC) proposed an index called the gamma index $\left(\mathrm{I}_{\gamma}\right)$ to verify whether the guidelines of EC for building material usage are met. $\mathrm{I}_{\gamma}$ is calculated using the following formula [13]:

$$
\mathrm{I} \gamma=\mathrm{A}_{\mathrm{Ra}} / 300+\mathrm{A}_{\mathrm{Th}} / 200+\mathrm{A}_{\mathrm{K}} / 3000 \leq 1
$$

\subsubsection{Hazard Indices for Internal Alpha Radiation (Hin \& Ia)}

Internal exposure arises from the intake of terrestrial radionuclides by inhalation and ingestion. Doses by inhalation result from the presence in air of dust particles containing radionuclides of the ${ }^{238} \mathrm{U}$ and ${ }^{232} \mathrm{Th}$ decay chains. The dominant components of inhalation exposure are the short-lived decay products of radon $\left({ }^{222} \mathrm{Rn}\right)$. In addition to the external hazard, radon and its short-lived products are also hazardous to the respiratory organs. To assess the internal exposure to ${ }^{222} \mathrm{Rn}$ gas and its daughter products the internal hazard index has been defined by the following formula [10]:

$$
\operatorname{Hin}=\mathrm{A}_{\mathrm{Ra}} / 185+\mathrm{A}_{\mathrm{Th}} / 259+\mathrm{A}_{\mathrm{K}} / 4810
$$

This quantity should be less than unity for the safe use of materials in the construction of buildings. Excess alpha radiation caused by the inhalation of radon liberated from building materials can be estimated using the alpha index $\left(I_{\alpha}\right)$, which has been defined by the following formula [14]:

$$
\mathrm{I}_{\alpha}=\mathrm{A}_{\mathrm{Ra}} / 200 \leq 1
$$

\section{Results \& Discussion}

The results obtained for the activity concentrations of ${ }^{226} \mathrm{Ra},{ }^{232} \mathrm{Th}$ and ${ }^{40} \mathrm{~K}$ in the eight various cement samples are presented in Table 1. They were analysed by gamma-ray spectrometry system and ranged from 5.8 to $43.17 \mathrm{~Bq} \mathrm{~kg}^{-1}$, with an average value $24.25 \mathrm{~Bq} \mathrm{~kg}^{-1}$ for ${ }^{226} \mathrm{Ra}$, from 0.99 to $55.79 \mathrm{~Bq} \mathrm{~kg}^{-1}$, with an average value $25.41 \mathrm{~Bq} \mathrm{~kg}^{-1}$ for ${ }^{232} \mathrm{Th}$ and from 53.28 to $185.34 \mathrm{~Bq} \mathrm{~kg}^{-1}$, with an average value

\begin{tabular}{|c|c|c|c|c|c|}
\hline \multirow{2}{*}{ Sample Code } & \multirow{2}{*}{ Sample Name } & \multicolumn{3}{|c|}{ Radioactivity Concentration ( $\left.\mathrm{Bq} \mathrm{Kg}^{-1}\right)$} & \multirow{2}{*}{$\operatorname{Raeq}\left(\mathrm{Bq} \mathrm{Kg} \mathbf{~ g}^{-1}\right)$} \\
\hline & & ${ }^{226} \mathbf{R a}$ & ${ }^{232} \mathrm{Th}$ & ${ }^{40} \mathbf{K}$ & \\
\hline CEM1 & Kerkuk 1 & $9.43 \pm 0.52$ & $54.31 \pm 7.75$ & $185.34 \pm 11.03$ & 101.36 \\
\hline CEM2 & Kerkuk 2 & $10.16 \pm 0.66$ & $26.07 \pm 0.93$ & $177.82 \pm 10.11$ & 61.13 \\
\hline CEM3 & Basra 1 & $40.91 \pm 4.65$ & $2.03 \pm 0.44$ & $70.32 \pm 6.4$ & 49.23 \\
\hline CEM4 & Basra 2 & $34.66 \pm 3.54$ & $0.99 \pm 0.26$ & $66.97 \pm 6.12$ & 41.23 \\
\hline CEM5 & Najaf 1 & $42.85 \pm 1.47$ & $5.92 \pm 0.71$ & $56.34 \pm 6.7$ & 55.65 \\
\hline CEM6 & Najaf 2 & $43.17 \pm 1.32$ & $5.74 \pm 0.56$ & $53.28 \pm 6.03$ & 55.48 \\
\hline CEM7 & Kuffa 1 & $7.03 \pm 0.46$ & $52.43 \pm 1.22$ & $63.74 \pm 5.89$ & 86.91 \\
\hline \multirow[t]{2}{*}{ CEM8 } & Kuffa 2 & $5.8 \pm 0.55$ & $55.79 \pm 1.32$ & $71.53 \pm 6.09$ & 91.09 \\
\hline & Average & $24.25 \pm 1.45$ & $25.41 \pm 1.65$ & $93.17 \pm 7.30$ & 67.76 \\
\hline
\end{tabular}
93.17 $\mathrm{Bq} \mathrm{kg}^{-1}$ for ${ }^{40} \mathrm{~K}$..

Table 1. The radioactivity concentrations of 226Ra, 232Th and 40K radionuclides in cement samples.

The calculated values of the radium equivalent activities $\left(\mathrm{Ra}_{\mathrm{eq}}\right)$ for all the samples of cements are presented in Table 1 based on Eq.1. The highest value of $\mathrm{Ra}_{\mathrm{eq}}$ estimated in CEM1 is $101.36 \mathrm{~Bq} \mathrm{~kg}^{-1}$, which is significantly less than the upper limit of $370 \mathrm{~Bq} \mathrm{~kg}{ }^{-1}$ [10] and thus does not pose any radiological hazard when used for the construction of buildings. Figure 2 is shown the values of the radium equivalent activity in cement samples.

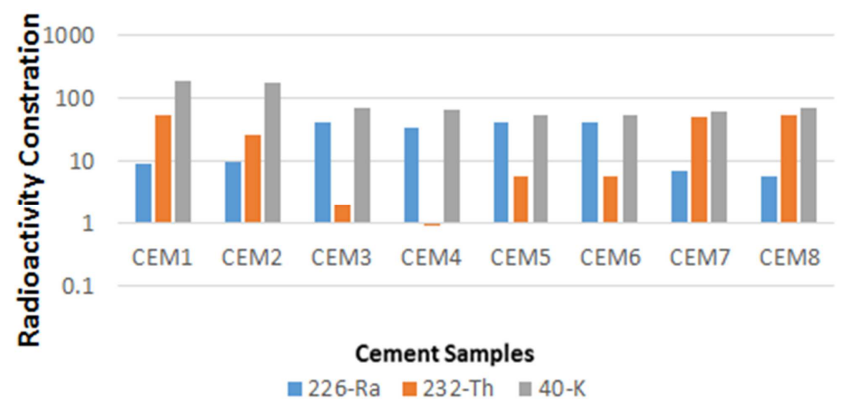

Figure 1. The radioactivity concentrations of ${ }^{226} \mathrm{Ra},{ }^{232} \mathrm{Th}$ and ${ }^{40} \mathrm{~K}$ radionuclides in cement samples.

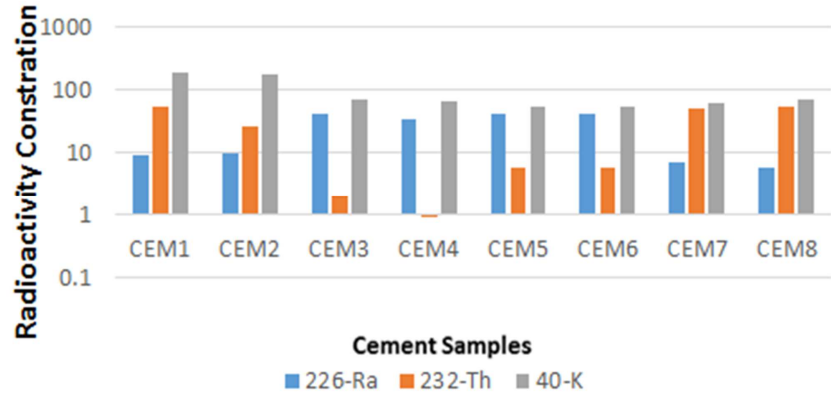

Figure 2. The values of radium equivalent activity in cement samples.

Table 2 is shown the value of the gamma dose rate (D) in air for the cement samples. Where the maximum gamma dose rate is $54.71 \mathrm{nGy} \mathrm{h}^{-1}$ in CEM1 sample, while the minimum value found in CEM4 was approximately 21.42 nGy $\mathrm{h}^{-1}$. The estimated mean value of $\mathrm{D}$ in the studied samples is $35.84 \mathrm{nGy} \mathrm{h}^{-1}$, which is within the world average indoor absorbed gamma dose rate of $55 \mathrm{nGy} \mathrm{h}^{-1}$ [12]. Figure 3 is shown the values of the absorbed dose rate with cement samples. The estimated mean value of the annual effective 
dose equivalent (AEDE) which are presented in Table 2, based on Eq. 3 and Eq. 4 were 0.05 (outdoor), 0.18 (indoor) $\mathrm{mSv} \mathrm{y}^{-1}$, respectively, are below the recommended limits for annual effective dose of the $1 \mathrm{mSv} \mathrm{y}^{-1}$ approved by the
International Commission on Radiological Protection (ICRP) as the maximum annual dose to the members of the public [12]. Figure 4 is shown the various samples of cement along with the annual effective dose rate and hazard indices.

Table 2. The calculated values of absorbed dose rate, annual effective dose, alpha index, gamma index and hazard index, in sample.

\begin{tabular}{|c|c|c|c|c|c|c|c|c|}
\hline \multirow{2}{*}{$\begin{array}{l}\text { Sample } \\
\text { Code }\end{array}$} & \multirow{2}{*}{ Sample Name } & \multirow{2}{*}{ (D) $\left(\mathrm{nGy} \mathrm{h} \mathbf{h}^{-1}\right)$} & \multicolumn{2}{|c|}{$(\mathrm{AEDE})\left(\mathrm{mSv} \mathrm{y}^{-1}\right)$} & \multicolumn{2}{|c|}{ Hazard Index } & \multirow{2}{*}{$\begin{array}{l}\text { Alpha Index } \\
\mathbf{I}_{\alpha}\end{array}$} & \multirow{2}{*}{ Gamma Index $\mathbf{I}_{\gamma}$} \\
\hline & & & outdoor & indoor & $\mathbf{H}_{\mathrm{ex}}$ & $\mathbf{H}_{\text {in }}$ & & \\
\hline CEM1 & Kerkuk 1 & 54.71 & 0.07 & 0.27 & 0.27 & 0.30 & 0.05 & 0.36 \\
\hline CEM2 & Kerkuk 2 & 33.52 & 0.04 & 0.16 & 0.17 & 0.19 & 0.05 & 0.22 \\
\hline CEM3 & Basra 1 & 25.49 & 0.03 & 0.13 & 0.13 & 0.24 & 0.20 & 0.17 \\
\hline CEM4 & Basra 2 & 21.42 & 0.03 & 0.11 & 0.11 & 0.21 & 0.17 & 0.14 \\
\hline CEM5 & Najaf 1 & 28.68 & 0.04 & 0.14 & 0.15 & 0.27 & 0.21 & 0.19 \\
\hline CEM6 & Najaf 2 & 28.55 & 0.04 & 0.14 & 0.15 & 0.27 & 0.22 & 0.19 \\
\hline CEM7 & Kuffa 1 & 46.02 & 0.06 & 0.23 & 0.23 & 0.25 & 0.04 & 0.31 \\
\hline CEM8 & Kuffa 2 & 48.32 & 0.06 & 0.24 & 0.25 & 0.26 & 0.03 & 0.32 \\
\hline Average & & 35.84 & 0.05 & 0.18 & 0.18 & 0.25 & 0.97 & 0.24 \\
\hline
\end{tabular}

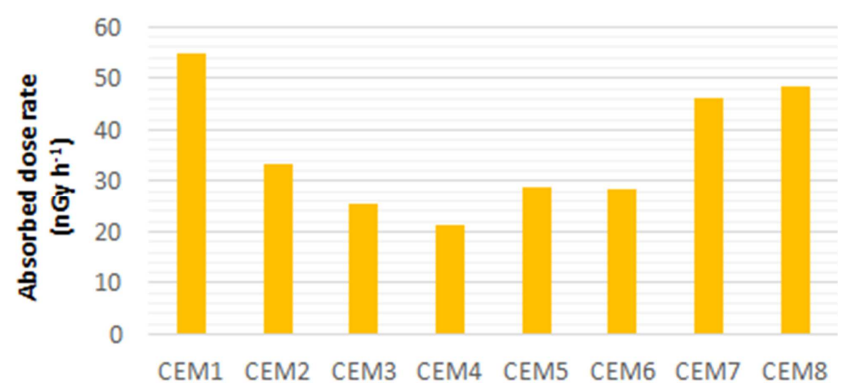

Figure 3. The values of the absorbed dose rate in the cement samples.

In this study, the results of Hex based on Eq. (5) are given in Table 2. The values (Shows in Figure 4) range from 0.11 to 0.27 , which means that all of them are below the recommended level of 1 . The values of Hin based on Eq. (7) are presented in table 2. From the table, it can be seen that the values range from 0.19 to 0.30 , which means that all of them are below the recommended level of 1 [10].

The computed values of the alpha and gamma indices $\left(\mathrm{I}_{\alpha}\right.$ and $\mathrm{I}_{\gamma}$ ) are also given from Table 2 . The highest values (Shows in Figure 4) of $\mathrm{I} \alpha$ and $\mathrm{I}_{\gamma}$ are 0.22 and 0.36 , respectively, the obtained values of $\mathrm{I} \alpha$ and $\mathrm{I}_{\gamma}$ in the present study are lower than the recommended values of 1 [13].

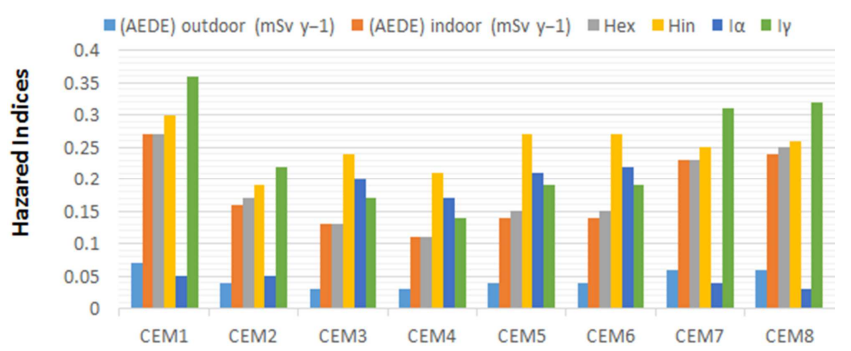

Figure 4. The values of AEDE (outdoor), AEDE (indoor), Hex, Hin, alpha index and gamma index in the cement samples.

In Table 3, the mean values of the activity concentrations of ${ }^{226} \mathrm{Ra},{ }^{232} \mathrm{Th}$ and ${ }^{40} \mathrm{~K}$ and the radium equivalent activities (Raeq) determined in the current study for the cement samples are compared with other countries. The activity levels vary from one country to another, which can be attributed to differences in the contents of radioactive minerals and in the geological, geochemical and geographical origins of the raw materials, among other factors. This fact is important to consider in the section of suitable materials for use in building construction, especially those that exhibit large variations in their activities.

Table 3. Comparison of mean radioactivity concentrations of ${ }^{226} \mathrm{Ra},{ }^{232} \mathrm{Th}$ and ${ }^{40} \mathrm{~K}$ and $\mathrm{Ra} a_{\text {eq }}$ activity $\left(\mathrm{Bq}_{\mathrm{kg}}{ }^{-1}\right)$ in cement samples with some other countries of the world.

\begin{tabular}{llll}
\hline \multirow{2}{*}{ Country } & \multicolumn{3}{l}{ Radioactivity Concentration (Bq kg-1) } \\
\cline { 2 - 3 } & ${ }^{\mathbf{2 2 6} \mathbf{R a}}$ & ${ }^{\mathbf{2 3 2}_{\mathbf{2}}}$ & \\
\hline Present study & 24.25 & 25.41 & \\
Bangladesh [16] & $61.1 \pm 0.8$ & $79.9 \pm 1.2$ & 93.17 \\
China [17] & $68.3 \pm 3.6$ & $51.7 \pm 5.4$ & $1132.6 \pm 17.3$ \\
Egypt [18] & $134 \pm 67$ & $88 \pm 35$ & $173.8 \pm 8.6$ \\
Pakistan [19] & $37 \pm 3$ & $28 \pm 3$ & $416 \pm 162$ \\
Turkey [20] & $49.8 \pm 5.8$ & $17.3 \pm 2.2$ & $200 \pm 14$ \\
Vietnam [21] & $39.86 \pm 17.43$ & $39.86 \pm 17.43$ & $246.2 \pm 20.8$ \\
India [22] & $54 \pm 13$ & $65 \pm 10$ & $243.5 \pm 62.2$ \\
\hline
\end{tabular}

\section{Conclusion}

Gamma ray spectrometry was used to determine the radioactivity concentrations of ${ }^{226} \mathrm{Ra},{ }^{232} \mathrm{Th}$ and ${ }^{40} \mathrm{~K}$ in the studied samples of cement from the cement factories, Iraq. The results show that the activity concentrations of ${ }^{226} \mathrm{Ra}$, ${ }^{232} \mathrm{Th}$ and ${ }^{40} \mathrm{~K}$ were in the range of the typical world value. The radium equivalent activity, absorbed gamma dose rate in indoor air and the corresponding annual effective dose 
equivalent, the external and internal hazard indices, the alpha index (internal index) and the gamma activity concentration (gamma index) of the radiological parameters were calculated to qualify and quantify the radiological hazard associated with the studied cement. Hence, it is concluded that the radiological parameters obtained are normal and within the recommended limits. Therefore, the use of this cement samples under investigation in the construction of dwellings is considered to be safe for inhabitants.

\section{References}

[1] Ali, K. K., 2012. "Radioactivity in building material in Iraq". Radiat. Prot. Dosim. 148 (3), 372-379.

[2] Hussain, H. H., Hussain, R. O., Yousef, R. M. and Shamkhi, Q., 2010. "Natural radioactivity of some local building materials in the middle Euphrates of Iraq", Radio analytical and Nuclear Chemistry, Vol. 284, P: 43-47.

[3] Turhan, S., 2008."Assessment of the natural radioactivity and radiological hazards in Turkish cement and its raw materials". J. Environ. Radioact, Vol. 99, 404-414.

[4] Hany El-Gamal, Marwa Abdel Hamid, A. I. Abdel Mageed, A. L. El-Attar., 2012. ${ }^{1226} \mathrm{Ra},{ }^{232} \mathrm{Th}$ and ${ }^{40} \mathrm{~K}$ analysis in water samples from Assiut, Egypt". XI Radiation Physics \& Protection Conference, 106-106, (2012).

[5] United Nations Scientific Committee on the Effects of Atomic Radiation (UNSCEAR), Sources, Effects and Risks of Ionizing Radiation. New York (1988).

[6] United Nations Scientific Committee on the Effects of Atomic Radiation (UNSCEAR), Sources and Effects of Ionizing Radiation. Report to the General Assembly, with scientific annexes, United Nations, New York (2008).

[7] Rahman SU, Rafique M, Jabbar A, Matiullah, 2013. "Radiological hazards due to naturally occurring radionuclides in the selected building materials used for the construction of dwellings in four districts of the Punjab province", Pakistan. Radiat Prot Dosim; 153(3): 352-360.

[8] R. Ravisankar, K. Vanasundari, A. Chandrasekaran, A. Rajalak-shmi, M. Suganya, P. Vijayagopal, V. Meenakshisundaram, Measurement of natural radioactivity in building materials of Namakkal, Tamilnadu, India using gamma ray spectrometry, Appl. Radiat. Isot. 70 (2012) 699704.
[9] Genie 2000 operations tools manual, Canberra Industries Inc, USA (2001).

[10] J. Beretka, P. J. Mathew, Natural radioactivity of Australian building materials, industrial wastes and by-products, Health Phys. 48(1985) 87-95.

[11] INTERNATIONAL ATOMIC ENERGY AGENCY, Protection of the Public against Exposure Indoors due to Radon and Other Natural Sources of Radiation, IAEA Specific Safety Guide No. SSG-32, IAEA, Vienna (2015).

[12] UNSCEAR United National Scientific Committee on the Effects of Atomic Radiation Sources and Risks of Ionizing Radiation, Report to the General Assembly with Annexes, United Nations, New York, 2000.

[13] EC (European Commission), Radiation Protection, 112 Radiological Protection Principles Concerning the Natural Radioactivity of Building Materials, Directorate General Environment. Nuclear Safety and Civil Protection, 1999.

[14] V. R. Krieger, Radioactivity of construction materials, Betonwerk Fertigteil Technol. 47 (1981) 468-473.

[15] Roy, S.; Alam, M. S.; Begum, M.; and Alam, B. "Radioactivity in building materials used in and around Dhaka city". Radiat. Prot. Dosim, Vol. 114, 527-532, (2005).

[16] Lu, X.; Yang, G. and Ren, C. "Natural radioactivity and radiological hazards of building materials in Xianyang, China". Radiat. Phys. Chem, Vol. 81, 780-784, (2012).

[17] Ahmed NK. Measurement of natural radioactivity in building materials in Qena city, Upper Egypt. J Environ Radioact. 2005; 3: 91-99.

[18] Rahman SU, Rafique M, Jabbar A, Matiullah. Radiological hazards due to naturally occurring radionuclides in the selected building materials used for the construction of dwellings in four districts of the Punjab province, Pakistan. Radiat Prot Dosim. 2013; 153(3): 352-360.

[19] Erees FS, Dayanikli SA, Çam S. Natural Radionuclides in the Building Materials used in Manisa City, Turkey. Indoor Built Environ. 2006; 15(5): 495-498.

[20] Mollah AS, Ahmed GU, Husain SR, Rahman MM. The Natural Radioactivity of some Building Materials used in Bangladesh. Health Phys. 1986; 50(6): 849-851. PMID: 3710795 .

[21] Khandaker MU, Jojo PJ, Kassim HA, Amin YM. Radiometric analysis of construction materials using HPGe gamma-ray spectrometry. Radiat Prot Dosim. 2012; 152: 33-37. 